\title{
Remoção de corpo estranho em face devido acidente doméstico: relato de caso
}

Foreign body removal in the face due to domestic accident: case report

Extracción de cuerpos extraños en la cara debido a un accidente doméstico: reporte de caso

\section{Maylson Alves Nogueira BARROS ${ }^{1}$} Vitor Bruno TESLENCO ${ }^{1}$

Herbert de Abreu CAVALCANTI ${ }^{2}$

Everton Floriano PANCINI ${ }^{3}$

Guilherme Nucci dos REIS ${ }^{4}$

${ }^{1}$ Residência em Cirurgia e Traumatologia Bucomaxilofacial pelo Hospital Santa Casa de Campo Grande/MS

${ }^{2}$ Doutorando em Implantodontia pelo Centro de Pesquisas Odontológicas- São Leopoldo Mandic

${ }^{3}$ Especialista em Cirurgia e Traumatologia Bucomaxilofacial pelo Associação Paulista de Cirurgiões Dentistas(1985)

${ }^{4}$ Preceptor do Programa de Residência em Cirurgia e Traumatologia Bucomaxilofacial pelo Hospital Santa Casa de Campo Grande/MS

\section{Resumo}

Introdução: $\mathrm{O}$ aumento da idade é um dos fatores que causam inaptidão e institucionalização em pacientes geriátricos, o traumatismo decorrente de acidente doméstico pode levar a óbito. Os ferimentos por corpos estranhos são perigosos quando lesionado estruturas vitais. Objetivo: Descrição de um relato de caso de um paciente submetido cirurgia para remoção de um corpo estranho cravado na face. Relato de caso: Paciente com história de queda própria altura, durante atividade doméstica, foi diagnosticado com um objeto estranho em face, sendo submetido a remoção cirúrgica sob anestesia geral. Conclusão: Os pacientes com traumatismo facial devem ser submetidos avaliação primaria sistemática e lesões perfurativas por objetos estranhos em órgãos vitais necessitam de tratamento imediato, a remoção cirúrgica na maioria das vezes é necessária.

Descritores: Ferimentos e Lesões; Corpos Estranhos; Relatos de Casos.

\section{Abstract}

Introduction: Increasing age is one of the factors that cause disability and institutionalization in geriatric patients, trauma resulting from a domestic accident can lead to death. Foreign body injuries are dangerous when injured vital structures. Objective: Description of a case report of a patient undergoing surgery to remove a foreign body stuck in the face. Case report: A patient with a history of falling from a height, during domestic activity, was diagnosed with a foreign object in the face and underwent surgical removal under general anesthesia. Conclusion: Patients with facial trauma should undergo a primary systematic evaluation and perforating injuries by foreign objects in vital organs require immediate treatment, surgical removal is most often necessary.

Descriptors: Wounds and Injuries; Foreign Bodies; Case Reports.

\section{Resumen}

Introducción: el aumento de la edad es uno de los factores que causan discapacidad e institucionalización en pacientes geriátricos, el trauma resultante de un accidente doméstico puede conducir a la muerte. Las lesiones por cuerpos extraños son peligrosas cuando se lesionan estructuras vitales. Objetivo: Descripción de un informe de caso de un paciente sometido a cirugía para extraer un cuerpo extraño atrapado en la cara. Informe del caso: un paciente con antecedentes de caída desde una altura, durante la actividad doméstica, fue diagnosticado con un objeto extraño en la cara y se sometió a extracción quirúrgica bajo anestesia general. Conclusión: Los pacientes con trauma facial deben someterse a una evaluación sistemática primaria y las lesiones perforantes por objetos extraños en órganos vitales requieren tratamiento inmediato, la extracción quirúrgica es a menudo necesaria.

Descriptores: Heridas y Traumatismos; Cuerpos Extraños; Informes de Casos.

INTRODUÇÃO

\section{O aumento da idade é um dos fatores} que causam inaptidão e institucionalização em pacientes geriátricos, o traumatismo decorrente de acidente doméstico são um dos problemas, devido alterações visuais, musculoesqueléticas, diminuição da visão e deterioração dos reflexos $^{1}$. As complicações como infecções, hemorragias, fraturas e feridas são achados comuns nestes pacientes, o traumatismo craniano estão associados à altas taxas de mortalidade ${ }^{1}$.

A face é uma das áreas mais exposta do corpo e feridas penetrantes causadas por objetos perfurantes, podem resultar rompimento desses objetos no interior dos tecidos, como corpos estranho e próximos a estruturas nobres ${ }^{2,3}$. A remoção destes corpos estranhos são desafio para cirurgião, levando em consideração o tamanho, proximidade com estruturas vitais e 0 acesso cirúrgico ao objeto $^{3,4}$.

\section{CASO CLÍNICO}

Paciente, sexo masculino, 65 anos de idade, encaminhado ao serviço de Cirurgia e Traumatologia Bucomaxilofacial da Associação Beneficente do Hospital Santa Casa de Campo Grande/MS, com história de queda própria altura, durante uma atividade doméstica. $O$ paciente queixava-se de dor, sangramento local, e ao exame clinico apresentava com um corpo estranho cravado na região facial, infraorbitário direito, com ferimento associado a um discreto sangramento no momento da avaliação (Figura 1).

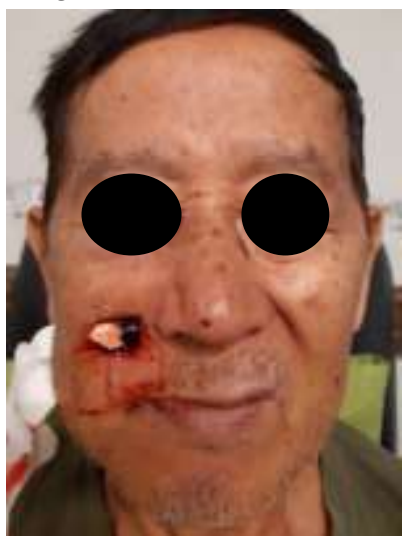

Figura 1: Fotografia frontal: corpo estranho cravado na face 


\section{A tomografia computadorizada} demonstrava corpo estranho de aproximadamente $15 \mathrm{~cm}$, atravessando todo seio maxilar direito até região nasofaringe (Figura 2). Após o diagnostico o paciente foi submetido anestesia geral para remoção do corpo estranho e reconstrução do ferimento (Figura 3).

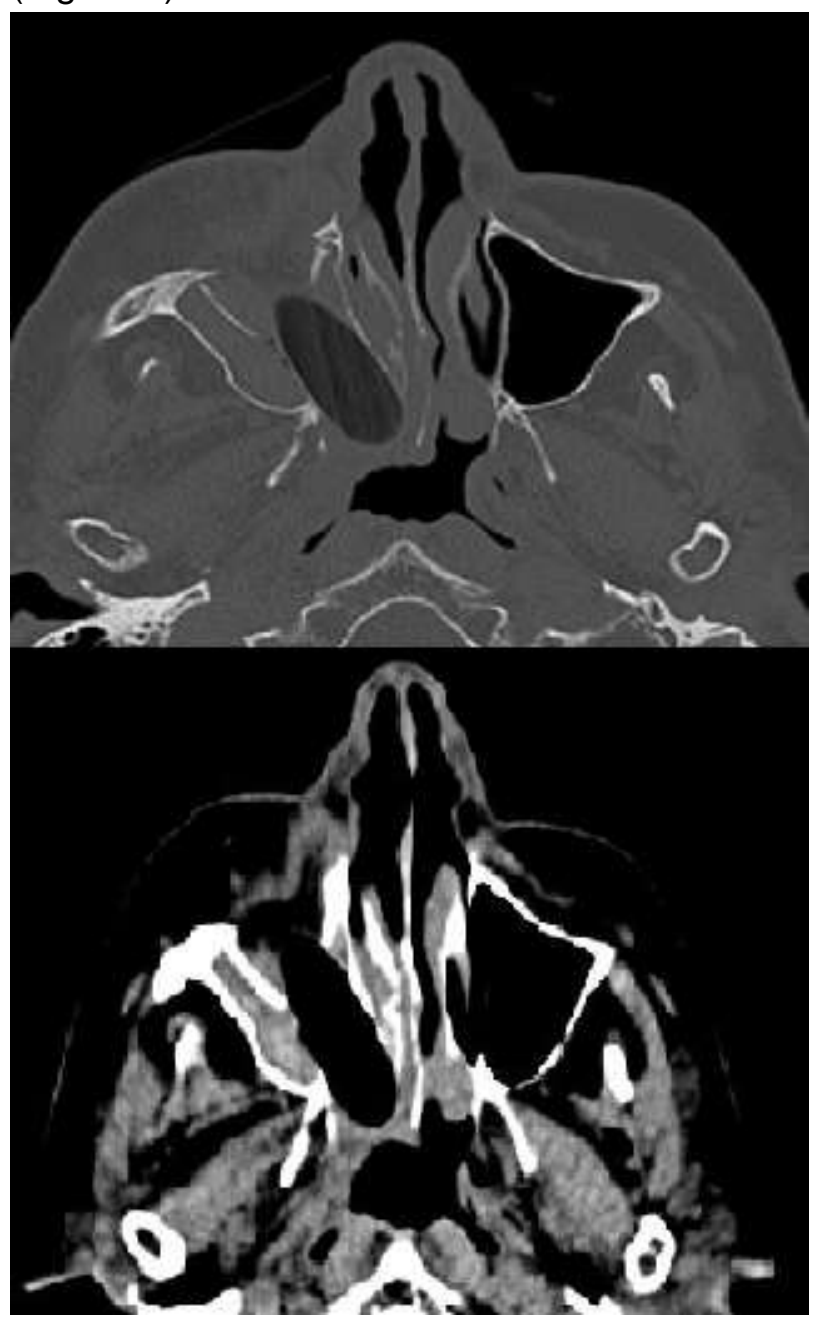

Figura 2: Tomografia computadorizada, corte axial, evidenciando corpo estranho.

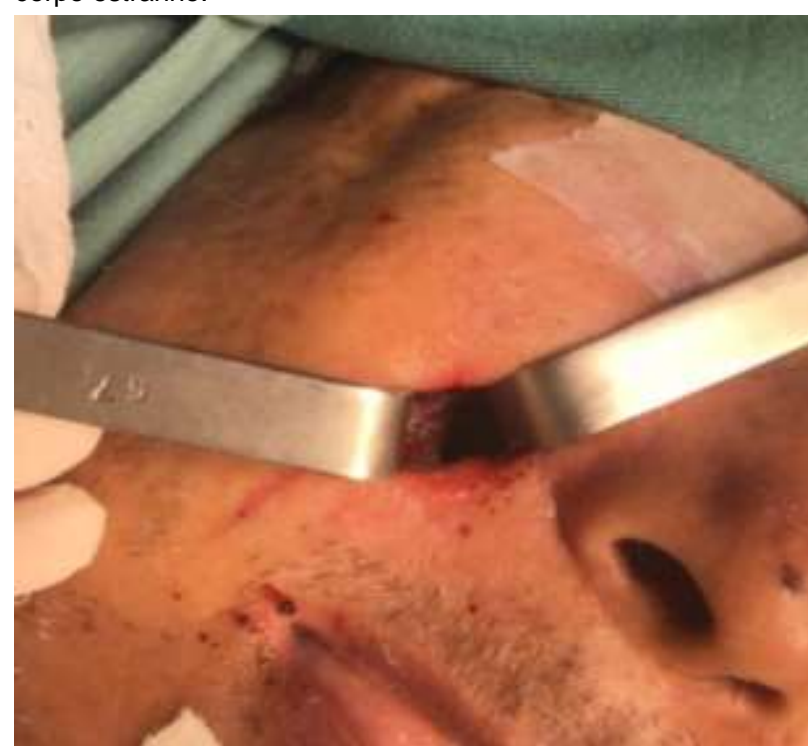

Figura 3: Aspecto imediato após remoção do corpo estranho, exploração e limpeza do ferimento.
DISCUSSÃO

O atendimento primário em pacientes politraumatizados é um requisito para manutenção da vida, o protocolo de ATLS deve ser realizado nos casos de emergência para evolução de um bom prognostico. O exame clinico deve ser bem detalhado, com avaliação geral do quadro do paciente ${ }^{5,6}$. O paciente supracitado foi encaminhado ao serviço especializado para atendimento e remoção cirúrgica do corpo estranho, aonde se apresentava consciente, orientado, estável hemodinamicamente, com discreto sangramento região infraorbitaria direita associado quadro álgico na região, o mesmo foi internado e submetido cirurgia para remoção.

Em um estudo Gioffrè-Florio e colaboradores em 2018, foram avaliados 4554 traumas geriátricos. Segundo os autores, os resultados demonstraram o sexo feminino como prevalente e as idades variaram entre 65 a 103 anos. Em relação ao tipo de traumatismo, o cranioencefalico foi mais comum, sendo que o trauma facial frequentemente estava associado ao traumatismo cranioencefalico ${ }^{1,7}$. O caso relatado é um paciente do sexo masculino, com história de acidente doméstico com traumatismo facial isolado, negava perda de consciência local, náuseas e ou episódios de êmeses, com um corpo estranho cravado região seio maxilar até próximo base do crânio.

O conhecimento da etiologia do trauma auxilia a solicitação de exames adequados, visto que alguns tipos de materiais se evidenciam de maneira diferente em exames imaginológicos. A tomografia computadorizada, ressonância magnética e ultrassonografia são os mais indicados para estes casos, apesar da madeira não se evidenciar facilmente na tomografia devido densidade, foi suficiente para auxilio no diagnóstico e tratamento deste paciente ${ }^{4}$.

As perfurações na região facial, próximos às estruturas nobres, podem necessitar de avaliações de múltiplas especialidades. Os corpos estranhos em geral, devem ser removidos, devido riscos de inflamações e infecção, os casos devem ser avaliados e se optado por não remover, deve se realizar o acompanhamento clinico e imaginologico ${ }^{3,5-8}$. No caso descrito, optou-se, com sucesso, pela remoção cirúrgica do corpo estranho sob anestesia geral. O paciente permaneceu em acompanhamento clinico e imaginológico, sem sinais ou sintomas de complicações. 


\section{CONSIDERAÇÕES FINAIS}

A abordagem aos pacientes com história de traumatismo facial deve incluir avaliação primaria para diagnostico e determinação de risco do quadro de gravidade. $\mathrm{O}$ aumento da idade contribui significativamente com acidentes domésticos. $O$ tratamento cirúrgico para remoção dos corpos estranhos deve ser avaliado com boa anamnese e diagnostico das regiões anatômicas envolvidas, podendo requerer abordagem multiprofissional. $O$ prognostico geralmente é favorável se não houver envolvimento de estruturas vitais.

REFERÊNCIAS

1. Gioffrè-Florio $M$, Murabito LM, Visalli $C$, Pergolizzi FP, Famà F. Trauma in elderly patients: a study of prevalence, comorbidities and gender differences. G Chir. 2018;39(1):3540.

2. 2 - Villarmé A, Savoldelli C, Jean-Baptiste E, Guevara N. Multidisciplinary surgical management of an unusual penetrating foreign body of the face. Eur Ann Otorhinolaryngol Head Neck Dis. 2018;135(5):361-63.

3. Al-Ahmady HH, El Sayed M, Fereir A, Ekram A, Mousa K. Removal of large impacted foreign body from the base of the skull through submandibular access: A multidisciplinary approach. Int J Surg Case Rep. 2018;50:21-4.

4. 4 -Melo MN, Pantoja LN, de Vasconcellos SJ, Sarmento VA, Queiroz CS. Traumatic Foreign Body into the Face: Case Report and Literature Review. Case Rep Dent. 2017;2017:3487386.

5. Kanu LN, Liu CY, Oh DJ, Maclntosh PW, Setabutr P. Self-insertion of foreign bodies into the orbit and periocular tissue. Orbit. 2019;38(6):486-91.

6. Blackhall KK, Laraway DC. Penetrating retroorbital foreign body - large glass shards: A maxillofacial surgery case report. SAGE Open Med Case Rep. 2016;4:2050313X15622890.

7. Pessoa Neto JV, Cetira Filho EL, Sampaio FD, Mello MJR, Menezes Junior JMS. Removal of Foreign Bodies in Orbit-Zygomatic-Maxillary Complex. J Craniofac Surg. 2019;30(7):e598e600.

8. Barbosa S, Polo TOB, Momesso GAC, Sousa CA, Silva WPP, Bassi APF et al. Feixe de luz como auxiliar na remoção de corpo estranho no seio maxilar. Inovação técnica em cirurgia e implantologia. Arch Health Invest. 2018;7(Spec Iss 3):216.

\section{CONFLITO DE INTERESSES}

Os autores declaram não haver conflitos de interesse

\section{AUTOR PARA CORRESPONDÊNCIA}

\section{Maylson Alves Nogueira Barros}

Rua Rui Barbosa, n 4744, apartamento 71 - Centro 79002-367 - Campo Grande - MS, Brasil 67 99677-5267

E-mail: maylson.bucomaxilofacial@gmail.com 